Para citar este artículo: Molina Giménez, A. (2019). Los caudales ecológicos en la planificación hidrológica. Reflexiones a la luz de la Sentencia del Tribunal Supremo 309/2019 de 11 de marzo, relativa al plan hidrológico del Tajo y sus posibles impactos en el Trasvase Tajo-Segura. Sostenibilidad: económica, social y ambiental, 1, 1330. https://doi.org/10.14198/Sostenibilidad2019.1.02

Financiación: Cátedra del Agua de la Universidad de Alicante-Diputación Provincial de Alicante (2019).

\title{
Los caudales ecológicos en la planificación hidrológica. Reflexiones a la luz de la Sentencia del Tribunal Supremo 309/2019 de 11 de marzo, relativa al plan hidrológico del Tajo y sus posibles impactos en el Trasvase Tajo-Segura
}

The ecological flows in the hydrological planning. Reflections in light of the
Supreme Court Judgement 309/2019, March 11th, related to the River Tajo
Hydrological Plan and its possible impacts on the Tajo-Segura Water Project

$\begin{array}{r}\text { Andrés Molina Giménez } \\ \text { Profesor titular de Derecho Administrativo, Universidad de Alicante, España } \\ \text { andres.molina@ua.es }\end{array}$
https://orcid.org/0000-0002-0088-4374

\section{RESUMEN}

El artículo analiza la reciente Sentencia del Tribunal Supremo 309/2019 de 11 de marzo, por la que se anula el plan hidrológico de la demarcación del Tajo por no contener una determinación concreta de los caudales ecológicos en cuatro masas de agua estratégicas. El interés del trabajo radica en la potencial afección que podría tener la fijación desproporcionada de tales volúmenes en los usuarios del Trasvase Tajo Segura, cuyos aprovechamientos dependientes del Trasvase están en función del volumen de recursos almacenados en el Alto Tajo. El incremento de estos caudales supondría mayores desembalses y, potencialmente, menores trasvases al Segura. Al hilo de esta cuestión se analizan los aspectos fundamentales del régimen jurídico de los caudales ecológicos, el elevado componente discrecional de su fijación, y la potencial responsabilidad patrimonial derivada de su implantación.

Palabras clave: caudal ecológico; planificación hidrológica; trasvase Tajo-Segura; Sentencia Tribunal Supremo. 


\begin{abstract}
The article analyzes the recent Sentence of the Supreme Court 309/2019, March 11th, which overturns several articles of the Tajo River Basin Hydrological Plan for not containing a concrete determination of the ecological flows in four strategic water masses. The interest of the work lies in the potential impact that the disproportionate fixation of such volumes could have on the users of the Tajo Segura Transfer, whose rights are highly dependent on the volume of resources stored in the Alto Tajo. The increase of these flows would lead to greater discharges from the reservoirs and as a result, potentially, smaller transfers to the Segura. In line with this issue, the fundamental aspects of the legal framework governing ecological flows, the high discretionary component of their fixation, and the potential strict liability derived from their implementation are analyzed.
\end{abstract}

Keywords: ecological flows; hydrological planning; Tagus-Segura interbasin transfer; Supreme Court Judgement.

\title{
1. Introducción
}

La legislación europea, y en particular la Directiva Marco, no establece la necesidad de fijar un caudal ecológico determinado en las masas de agua superficiales. Apela sin embargo al mantenimiento del buen estado ecológico de todas las masas, con independencia de su naturaleza superficial o subterránea. El Texto Refundido de la Ley de aguas, sin embargo, sí que acoge este concepto, que en buena medida traslada dicha exigencia en el aspecto cuantitativo. El caudal ecológico, entendido como un caudal mínimo circulante que resulta necesario para el mantenimiento de la flora y fauna de los ríos, se considera además como una prioridad; de hecho, no es tratado como un uso, sino como una restricción de los sistemas de explotación

La fijación concreta del caudal ecológico debe realizarse en sede de planificación hidrológica de demarcación (Embid Irujo, 1994). Estos planes son los que están en mejores condiciones para establecer el volumen ecológico, puesto que en el proceso de planificación se integran tanto los análisis técnicos pertinentes como los resultados de la participación pública.

No cabe duda de que en la fijación del caudal ecológico hay un componente de discrecionalidad ciertamente amplio. El propio Tribunal Supremo, como veremos, llega a admitir que en el proceso de valoración discrecional se integran elementos de oportunidad, lo que nos sitúa mucho más allá de la mera discrecionalidad técnica. Si se presta atención al procedimiento de planificación, y sin ir más lejos, a los documentos fundamentales que lo conformen, como son los esquemas de temas importantes (ETI), veremos que se plantean escenarios de amplísima discrecionalidad, pudiendo optarse por maximizar los planteamientos puramente ambientales o, por el contrario, dar más peso a los factores de carácter socioeconómico. En ese amplio marco, cualquier decisión del planificador, siempre que esté adecuadamente motivada, resultará perfectamente admisible.

Estas cuestiones se barajan en la Sentencia del Tribunal Supremo que inspira el presente artículo, emitida con motivo de la impugnación de diversos artículos del Plan Hidrológico de la Demarcación del Tajo (PHT). La ausencia de caudales ecológicos en el Plan, que sólo incluye caudales circulantes, merece el reproche del Alto Tribunal, que acuerda su anulación ordenando a la Administración la determinación de caudales ecológicos reales. Cuestión bien distinta será la cuantificación que el próximo plan hidrológico haga de los 
mismos, aspecto en el que el Tribunal no puede entrar por escapar a su función jurisdiccional.

Esa decisión, que con toda seguridad se tomará en el próximo ciclo de planificación hidrológica, resultará determinante para la continuidad del Trasvase Tajo-Segura, puesto que una elevación desproporcionada de dichos caudales podría impedir en la práctica autorizar trasvases (ante la disminución de las reservas en los embalses de cabecera) en condiciones hidrológicas ordinarias (Molina, Melgarejo y López, 2014). De ahí la importancia de esta Sentencia y la oportunidad de su análisis.

\section{Antecedentes analizados en la Sentencia}

La parte actora realiza en primer término una impugnación directa de diversos preceptos del PHT (Real Decreto 1/2016 de 8 de enero, relativo a las "disposiciones normativas del Plan hidrológico de la parte española de la demarcación hidrográfica del Tajo), en lo concerniente a diferentes temáticas: ausencia de caudales ecológicos (arts. 9 a 12); regulación de la asignación y reserva de recursos en el sistema de cabecera (art. 14 y apéndice 6.1); incumplimiento del mandato legal de determinar las aguas excedentarias en el PHT; ordenación del sistema de cabecera y Tajo medio contemplados en el Plan especial de sequía (Disposición final primera, apdo. 1.b. del Real Decreto 1/2016 y art. 20.1.b del PHT).

La impugnación directa de estos preceptos se realiza dentro del plazo de dos meses establecido con carácter general para el recurso frente a reglamentos. Contiene dos tipos de pretensión, la de anulación de todos los preceptos discutidos, que pretende su eliminación del ordenamiento jurídico, y la de plena jurisdicción (reconocimiento de derechos o situaciones jurídicas individualizadas), con la que se busca que el Tribunal sustituya a la Administración y fije directamente los caudales ecológicos de cuatro masas de agua estratégicas del río Tajo.

Se persigue la anulación de los diversos preceptos del PHT debido a que no concretan el caudal ecológico en 4 masas de agua estratégicas del río Tajo (Aranjuez, Toledo, Talavera y Almoguera), determinando únicamente unos caudales mínimos circulantes. El Tribunal acoge parcialmente la pretensión y declara la nulidad de los apartados 1, 3, 5, 6 y 7 del Artículo 9: "Regímenes de caudales ecológicos". Critica el Tribunal que la fijación de los caudales ecológicos alcanza a una parte muy poco significativa de la cuenca, quedando el $95 \%$ de las masas de agua excluidas de su determinación. Entre las masas que se califican como "estratégicas" (16), se pone el acento en la exclusión del régimen de caudales ecológicos de 4 de ellas, siendo que sólo en tres de los casos (Aranjuez, Toledo y Talavera) el PHT fija: "caudales mínimos circulantes, no ecológicos, sin variabilidad estacional". El Tribunal constata que en esas 4 masas de agua el PHT ha sustituido antijurídicamente el «régimen de caudales ecológicos mínimos» por una suerte de «caudales mínimos circulantes», a diferencia de las otras masas estratégicas para las que si establece un régimen de «caudales ecológicos mínimos trimestrales».

El Tribunal acude a varios elementos de prueba que demuestran que los valores indicados por el PHT no son caudales ecológicos sino caudales circulantes: 
En primer término, atendiendo a la documentación del anterior Plan de 2014 y del vigente de 2016, constata que la Confederación del Tajo había admitido expresamente que en estas 4 masas de agua estratégicas, en contraposición con las otras 16, «el régimen establecido no era de caudales ecológicos», y que el único régimen de caudales mínimos ecológicos era el aprobado en el Esquema de Temas Importantes (ETI) de noviembre de $2010\left(10,37 \mathrm{~m}^{3} / \mathrm{s}\right.$ en Almoguera, $10,86 \mathrm{~m}^{3} / \mathrm{s}$ en Aranjuez, $14,10 \mathrm{~m}^{3} / \mathrm{s}$ en Toledo y $15,92 \mathrm{~m}^{3} / \mathrm{s}$ en Talavera de la Reina) junto con su distribución trimestral.

Valora por otra parte el contenido del informe sobre la consulta pública del Plan de 2016, en el que se destaca que las citadas masas, en sus correspondientes puntos de control "presentan la singularidad de no tener fijados caudales ecológicos". En tres de ellas - Tajo en Aranjuez, Toledo y Talavera de la Reina - se habrían fijado unos caudales mínimos. En Almoguera no se habría fijado ni caudal mínimo ni ecológico según reza el documento. Continúa diciendo el informe: que en el ciclo de planificación "no se han fijado caudales ecológicos en el río Tajo (...). En su lugar, se mantienen los mínimos de $6 \mathrm{~m}^{3} / \mathrm{s}$ en Aranjuez (fijado por la Ley 52/1980), $10 \mathrm{~m} 3 / \mathrm{s}$ en Toledo (coincidente con el establecido en el Plan de 1998) y $10 \mathrm{~m}^{3} / \mathrm{s}$ en Talavera de la Reina, ya establecido en el vigente PHT2014.". Se recomendaba finalmente que al no ser caudales ecológicos se realizará un seguimiento específico de dichas masas de agua.

Otro importante elemento de prueba viene dado por el documento de discusión de caudales ecológicos de junio de 2013, en el que se exceptuaban los cuatro tramos del eje del Tajo del régimen de caudales ecológicos. Por otra parte, la Memoria de análisis de impacto normativo del proyecto de Real Decreto del Plan de 2016 recogía un "caudal mínimo de $6 \mathrm{~m}^{3} / \mathrm{s}$ en Aranjuez", especificando que "no se trataba de un caudal ecológico en el sentido general de los que fijan los planes hidrológicos, sino una condición fijada en la Ley 52/1980, de 16 de octubre, de Regulación del Régimen Económico de la Explotación del Acueducto TajoSegura".

Del análisis realizado por el Tribunal se pueden concluir dos consideraciones básicas: queda en primer término asentada la falta de concreción en el PHT de los caudales ecológicos de las 4 masas de agua estratégicas del río Tajo. En su lugar se habrían fijado únicamente caudales circulantes. Por otra parte, las cifras correspondientes a los caudales ecológicos de la ETI de 2010 no son más que datos incorporados a un documento de trámite elaborado con motivo de la tramitación del plan, que finalmente no fue aprobado en aquellos términos. Esas cifras no son en absoluto determinantes para la futura fijación del caudal ecológico de dichas masas en el próximo ciclo de planificación hidrológica, que deberá determinarse con base a los estudios técnicos y en función de los procesos de participación y concertación correspondientes

El recurso no se limita a plantear pretensiones de anulación, sino que va más allá, solicitando al Tribunal la adopción de medidas para el establecimiento de un régimen específico de caudales ecológicos. Sustancialmente, se solicita al tribunal que ordene en ejecución de sentencia la aplicación de los caudales ecológicos de la ETI de 2010. De acogerse tal pretensión, en el tramo desde el embalse de Almoguera hasta el embalse de Estremera el volumen del caudal ecológico quedaría en 13,71 $\mathrm{m}^{3} / \mathrm{s}$ en Aranjuez; 14,06 m³ en Toledo; hasta la confluencia del Guadarrama, 26,52 $\mathrm{m}^{3} / \mathrm{s}$; y desde Río Alberche hasta la cola del embalse de Azután 30,41 m³.

Este tipo de pretensiones de plena jurisdicción (reconocimiento de derechos o situaciones jurídicas individualizadas) son acogidas en muy limitadas situaciones, cuando no existe 
margen discrecional alguno de decisión y, de acuerdo con lo actuado en el expediente administrativo, el Tribunal sólo puede adoptar una única decisión materialmente justa. Este límite se impone a los Tribunales para evitar la denominada "sustitución judicial"; un excesivo "activismo" en la función jurisdiccional podría conducir a la "sustitución" por parte de los Tribunales de las funciones propias del poder ejecutivo. El Tribunal no debe ejercer una función que no le corresponde, como es la función de administrar, según resulta del art. 71.2 de la LJCA.

En coherencia con esta doctrina, la Sentencia razona que los caudales ecológicos, una vez han quedado anulados los caudales circulantes fijados en el PHT, deberán fijarse en el próximo ciclo de panificación. La cuantificación de los caudales ecológicos se realizará de manera participativa a través del procedimiento de planificación establecido en la legislación de aguas que, entre otros aspectos, busca seleccionar la opción materialmente más justa sobre la base del contraste de los informes técnicos, los documentos de la participación pública y la evaluación de diferentes alternativas.

Destaca el Tribunal que, en este caso, como en el conjunto de situaciones en que existen elementos discrecionales que deben tomarse en consideración, existe "un núcleo último de oportunidad en el que no cabe sustituir la decisión administrativa por una decisión judicial". El Tribunal señala, además: que "la revisión del régimen de caudales mínimos fijados en el PHT por una vía ajena al procedimiento establecido de revisión de los planes hidrológicos no puede llevarse a cabo sin tomar en consideración el resto de elementos del plan hidrológico, las afecciones que produciría en los usos existentes, y sin someterse al procedimiento establecido en nuestro ordenamiento para su revisión".

De todo ello, cabe concluir, al menos, en las siguientes consideraciones:

1. El Tribunal no puede imponer una determinada decisión cuando ésta depende de variables de carácter discrecional técnico, discrecional puro, e incluso de elementos de oportunidad relacionados con las diferentes opciones de política hidráulica.

2. La determinación de los caudales ecológicos por el Tribunal resultaría contraria al ordenamiento jurídico, puesto que comportaría el ejercicio de funciones materialmente administrativas o de gobernanza, lo que únicamente corresponde a la Administración hidráulica a través de los cauces legales establecidos.

3. El Tribunal reconoce la existencia de un amplísimo nivel de discrecionalidad en la concreción de los caudales ecológicos, con presencia incluso de elementos de "oportunidad". En las diferentes escalas de discrecionalidad, los elementos de oportunidad son los que ofrecen una mayor capacidad de optar entre soluciones igualmente justas. Su naturaleza se aproxima al terreno de las decisiones políticas, puesto que el ámbito decisional que se ofrece a la Administración es tan amplio que permite seleccionar opciones basadas en valoraciones de tipo político o al menos de lo que se ha venido a llamar "gobernanza".

4. Por otra parte, el Tribunal reconoce que en la fijación de caudales ecológicos deben tenerse en cuenta el conjunto de variables que afectan a la cuenca y no sólo, por tanto, la cuestión ecológica; entre esas variables entendemos que deben incluirse también las socioeconómicas, así como, teniendo en cuenta la peculiaridad del PHT, la existencia del Trasvase Tajo Segura que, no olvidemos, cuenta con un marco legal específico y unas 
reglas de explotación que tratan de compatibilizar los usos de la cuenca receptora con la necesaria protección de la cuenca cedente. De ahí que esas normas de explotación se definieran en su momento de una manera cautelosa, elevando las reservas en los embalses de cabecera, y realizando una cuidadosa regulación de los desembalses, todo ello para garantizar la prioridad de la cuenca cedente y el respeto a la calidad ambiental de las masas de agua del río Tajo.

La decisión final, evidentemente, será inmune al control jurisdiccional; la jurisprudencia viene utilizando diferentes "tests" de control de la discrecionalidad, que toman como referencia el control de los hechos, de los fundamentos de derecho, de los principios generales del derecho, así como del juicio de racionalidad y razonabilidad en la toma de decisiones.

Al margen de estas pretensiones principales, merece la pena mencionar que el Tribunal desestima la impugnación indirecta de varios preceptos del Real Decreto 773/2014 de 12 de septiembre, por el que se aprueban normas reguladoras del Trasvase Tajo-Segura. Este Decreto no fue recurrido dentro de los dos meses en que, de acuerdo con la legislación vigente, era posible ejercer acciones, por lo que la parte actora intentaba ahora realizar una impugnación indirecta de varios preceptos con motivo de la aprobación del PHT en 2016. La impugnación alcanza a los artículos 1, que regula las reglas de explotación del Trasvase TajoSegura, el artículo 2, que establece el modelo de predicción de aportaciones mensuales, y el artículo 4, que regula los desembalses de referencia.

Esta impugnación resulta a todas luces inviable puesto que el recurso indirecto contra reglamentos sólo es posible cuando se realiza un acto de aplicación que afecta de manera particular a un ciudadano o grupo de ciudadanos. Estos pueden recurrir dicho acto administrativo sobre la base de la posible ilegalidad del reglamento, obteniendo en su caso la anulación del acto y la posterior elevación de una cuestión de ilegalidad ante el Tribunal competente (en el caso de autos sería el propio Tribunal Supremo, por lo que dicha cuestión sería innecesaria), que podría dar lugar a la anulación de la disposición general con efecto erga omnes. Nada de esto concurre en el presente caso, donde lo que se impugna no es un acto administrativo sino una disposición de carácter general, como es el PHT, por lo que el recurso indirecto es inadmisible. Así lo confirma el Tribunal.

\section{La competencia estatal en la fijación de caudales ecológicos en cuencas intercomunitarias y su relación con otras competencias sectoriales}

De acuerdo con la distribución constitucional de competencias que se deriva del artículo 149.1.22, sólo al Estado le corresponde decidir sobre los caudales ecológicos en cuencas intercomunitarias, lo cual se materializa en el marco de la planificación hidrológica de cada demarcación. Esta no es en la actualidad una cuestión controvertida, aunque el Tribunal Constitucional tuvo en su día que clarificar el tema ante la pretensión de algunas Comunidades Autónomas de hacer valer otros títulos sectoriales de su competencia para asumir estas funciones. La Sentencia del Tribunal Constitucional núm. 110/1998 de 21 mayo, RTC \1998\110, declaraba que: "el régimen de caudales ecológicos ha de ser elaborado y aprobado para la cuenca hidrográfica en su conjunto, lo que impide una regulación independiente del mismo por cada una de las Comunidades Autónomas implicadas, cuyas competencias en materia de pesca fluvial y de protección de su ecosistema no pueden tener un alcance extraterritorial, ni interferir en la competencia del Estado sobre aprovechamientos hidráulicos, con la que necesariamente concurren". 
El Tribunal, sin embargo, llamaba a fijar estos caudales mediante la "mutua colaboración" con las Comunidades Autónomas. En otras palabras, éstas debían ser oídas en el proceso de planificación, sin que ello suponga condicionar la decisión del Organismo de Cuenca. Las Comunidades pueden establecer normas sobre caudales circulantes por razones relativas a la pesca fluvial, pero ello no puede ser más que una precisión "complementaria" del régimen de caudales ecológicos, toda vez que sólo el Organismo de Cuenca puede fijar estos últimos en el marco de la planificación hidrológica (Sentencia del TC de 22 de enero de 1998, RTC 1998). En otras palabras, sólo al Estado le corresponde la fijación de los caudales ecológicos a través de la planificación hidrológica, siendo que el resto de títulos competenciales autonómicos deben ejercerse respetando dicha competencia principal. La jurisprudencia, no obstante, admite que las leyes autonómicas puedan establecer caudales mínimos siempre que sean compatibles con los ecológicos, puesto que el establecimiento de una obligación legal puede justificarse en títulos competenciales distintos que concurren sobre un mismo espacio físico, sin que ello suponga la exclusión de ninguno de los títulos correspondientes, operando ambos de manera complementaria.

\section{El carácter instrumental y preferente del caudal ecológico}

El artículo 42.1.b.c) del TRLA (RDLeg. 1/2001 de 20 de julio) obliga a fijar los caudales ecológicos en los planes hidrológicos. En el precepto se incluye además una definición de los mismos: son los flujos necesarios para: "mantener como mínimo la vida piscícola que de manera natural habitaría o pudiera habitar en el río, así como su vegetación de ribera" Esta definición se complementa con otra, más específica, que establece el Real Decreto 907/2007, de 6 de julio, por el que se aprueba el Reglamento de la Planificación Hidrológica, según la cual, el caudal ecológico sería aquel: "caudal que contribuye a alcanzar el buen estado o buen potencial ecológico en los ríos o en las aguas de transición y mantiene, como mínimo, la vida piscícola que de manera natural habitaría o pudiera habitar en el río, así como su vegetación de ribera". Se acoge en esta segunda definición un nuevo elemento, como es la necesidad de que el caudal ecológico permita alcanzar el buen estado ecológico de la masa, lo que daría respuesta a las exigencias de la Directiva Marco; ello precisa, como mínimo, el mantenimiento de la biodiversidad del río.

En la jurisprudencia encontramos también algunas definiciones de caudal ecológico que pueden ayudar a delimitar su alcance. Así, la Sentencia del Tribunal Supremo de 21 de enero de 2015, RJ 2015/459, destaca su finalidad u objeto principal, que no es otro que mantener la integridad biológica del sistema: "el régimen de caudales ecológicos debe proporcionar condiciones de hábitat adecuadas según las necesidades de los ecosistemas presentes y ofrecer un patrón temporal de los caudales que permita la existencia, como máximo, de cambios leves en la estructura y composición de los ecosistemas acuáticos y hábitat asociados y permita mantener la integridad biológica del ecosistema. Y para conseguir esos objetivos se fija un orden de prioridad según se trate de zonas protegidas, masas de agua naturales y masas de agua muy modificadas".

Los caudales ecológicos, por otra parte, deben fijarse tanto en las masas en mal estado como en aquellas que presentan un buen estado; no es un simple instrumento de corrección del estado ecológico de las masas deterioradas, sino que también se fija con el objetivo de contribuir al mantenimiento y preservación de las masas que ya se encuentran en buenas 
condiciones, con un enfoque por tanto preventivo. En este sentido es clara la Sentencia de 21 de enero de 2015, RJ/2015/4591.

Otra de las cuestiones fundamentales es que, de acuerdo con el TRLA, los caudales ecológicos no constituyen un uso sino una restricción (Briso Montiano y García Jiménez, 2014). Esta restricción se impone con carácter general en los sistemas de explotación, de modo que el Organismo de Cuenca ha de descontarlos del balance de la cuenca a efectos del otorgamiento o modificación de las concesiones existentes (art. 59 y 98 TRLA). También la Ley 10/2001 de 5 de julio, del Plan Hidrológico Nacional, refuerza el carácter prevalente de estos caudales, considerándolos como una "limitación previa a los flujos del sistema de explotación que operará con carácter preferente a los usos contemplados en el sistema". Sólo resultarían preferentes los volúmenes destinados a abastecimiento humano (art. 26).

\section{La fijación de los caudales ecológicos en la planificación hidrológica de demarcación: nivel de detalle}

La Sentencia del Tribunal Supremo 309/2019 de 11 de marzo supone un cambio en la línea jurisprudencial existente con relación al nivel de detalle requerido en la planificación hidrológica en materia de caudales ecológicos. Así, la Sentencia del Tribunal Supremo de 25 de octubre de 2013 (RJ 2013, 7368), relativa a una impugnación del plan hidrológico de las cuencas internas de Cataluña, venía a decir que la determinación completa de los caudales ecológicos no correspondía necesariamente al plan hidrológico, pudiendo quedar diferida a un acto posterior, sin que ello pudiera suponer una mera remisión en blanco. ${ }^{2}$

Este criterio se reitera en la Sentencia del Tribunal Supremo de 8 abril 2014, RJ 2014\2594, en la que se evalúa la legalidad de un precepto del plan de Galicia-Costa, y donde se manifiesta que el plan no necesariamente ha de cuantificar el caudal ecológico en todos los tramos del río, siendo posible la indicación de caudales mínimos de carácter transitorio ${ }^{3}$. Esta

\footnotetext{
${ }^{1}$ Dice la Sentencia: “de la definición de caudal ecológico como, en general, de la finalidad de la planificación hidrológica no se deduce que las aguas en buen estado en sus diferentes modalidades deban quedar excluidas de la fijación de caudales ecológicos. A su vez, la planificación se predica tanto de las naturales como las muy alteradas, siendo la finalidad de protección y preservación más intensa para las primeras y para las muy alteradas los objetivos son menores".
}

\footnotetext{
${ }^{2}$ En este Sentido, la citada Sentencia declara: "la determinación de los caudales ecológicos o de mantenimiento en su totalidad no corresponde, necesariamente, al plan hidrológico, pues éste cumple con contener esa descripción general. Y esta descripción se realiza, precisamente, en el artículo 12 de las normas del plan hidrológico de las cuencas intracomunitarias de Cataluña que, además de habilitar al plan sectorial impugnado en la instancia, establece las necesidades del caudal circundante, la metodología para fijar el caudal de mantenimiento a aplicar en cada caso, la forma de realizarse para cada río y tramo de río, de acuerdo con el régimen hidrológico específico, la época del año, y su finalidad, entre otras (...) la habilitación del artículo 12 del Plan Hidrológico de tanta cita no es una remisión en blanco, como aduce la recurrente, ni lesiona el contenido legal obligatorio de los planes hidrológicos que fija el artículo 42.1 del TR de la Ley de Aguas (...).
}

${ }^{3}$ El Tribunal declara que: "la cuantificación del caudal en los respectivos tramos no necesariamente ha de figurar
en el Plan, se genera un vacío temporal en la protección ecológica de los cauces en tanto no se realiza aquella
determinación que justifica que dentro de las previsiones del Plan se incorporase un mínimo caudal que acuda
transitoriamente a proteger los cauces afectados, sin que en este mínimo quepa hacer las diferencias que debieran
resultar de los estudios específicos por tramos, puesto que su razón de ser es precisamente la de la ausencia
meramente circunstancial y transitoria de dichos estudios". Sigue diciendo la Sentencia que: "la concreción de
cada uno de los caudales ecológicos no es exigencia legal que figure en el Plan, de forma que, en su caso, será 
Sentencia fue anulada mediante Auto de 30 septiembre 2014, pero no por discrepar de su contenido sustantivo, sino en la medida en que no abordaba la impugnación de otros preceptos del Plan hidrológico, como pretendía la recurrente, vulnerando con ello el derecho a una tutela judicial efectiva. La doctrina de aquella Sentencia, de hecho, fue reiterada posteriormente por el Tribunal Supremo en la Sentencia de 12 diciembre 2014, RJ $2014 \backslash 6702$, que acuerda resolver el pleito en los mismos términos ya declarados en aquella ${ }^{4}$. Concluye el Tribunal que: "vistos los indicados antecedentes y la evidente cercanía entre los textos del artículo 12 del Plan Hidrológico de las Cuencas Internas de Cataluña y el 7 de Galicia-Costa, nuestra conclusión no puede ser otra que la de calificar a éste de ajustado a derecho en la perspectiva del cumplimiento del artículo 42.1.b.c) del TRLA, por lo que se refiere a su descripción general de los caudales ecológicos".

Frente a esta doctrina, el Tribunal Supremo, en la Sentencia que estamos analizando, prefiere anular el plan hidrológico de la cuenca del Tajo al estimar que la fijación de los caudales como "caudales circulantes" incumple la obligación del plan de fijar los caudales ecológicos.

\section{El carácter "discrecional-técnico", "discrecional puro" y de "oportunidad" de la fijación del caudal ecológico. La proporcionalidad y la vertiente socioeconómica como criterios de fijación del caudal ecológico. El límite de la arbitrariedad}

La fijación de los caudales ecológicos en la planificación no puede realizarse de manera indiciaria y sin la debida justificación. Por el contrario, los caudales ecológicos deben determinarse como resultado de estudios técnicos que han de realizarse en la cuenca correspondiente, así como del resultado de la participación pública y de un procedimiento de concertación (Sastre Beceiro, 2010); entran en juego componentes discrecionales, de gobernanza del agua o de oportunidad.

El artículo 59 del TRLA dice claramente que los caudales ecológicos se fijarán realizando: "estudios específicos para cada tramo de río". De esta determinación legal cabe destacar que nos situamos en un ámbito de clara discrecionalidad técnica, puesto que la norma exige la realización de "estudios específicos" que deberán redactarse por parte de técnicos en la materia con capacidad suficiente para interpretar las necesidades de la flora y fauna del espacio fluvial. Los caudales se definirán para cada tramo de río de acuerdo a criterios que permitan homogeneizar tramos con características y necesidades similares. Dichos estudios técnicos han de ser suficientemente exhaustivos y completos; en otro caso, los caudales ecológicos fijados por el plan podrían ser anulados por los Tribunales ${ }^{5}$.

cuando se realicen los estudios previstos en aquel cuando la interesada podrá objetar los defectos de participación en la implantación concertada que a su juicio se puedan producir".

${ }^{4}$ Dice el Tribunal: “comenzamos, siguiendo el orden en que aquella los trata en la demanda, por los referentes a los caudales ecológicos, extremo sobre el que nos hemos pronunciado en la sentencia anulada mediante el Auto antes citado y que al no estar afectado por la causa de nulidad de actuaciones que entonces acogimos, procede que acordemos resolverlo en los mismos términos"

5 En este sentido, un interesante ejemplo de anulación por no contemplar suficientemente determinadas afecciones derivadas del incremento del caudal circulante lo encontramos en la Sentencia del Tribunal Superior de Justicia de La Rioja 28/2004 de 9 de febrero, JUR 2004, 201419: "La Sala valorando que el único informe aportado que ha realizado un «estudio de campo» sobre la situación de determinadas especies piscícolas (visón europeo y nutria) en el río Najerilla es el aportado por la Comunidad Autónoma de la Rioja sin que los otros informes hayan valorado esta cuestión, además de los datos y razonamientos que dicho informe expresa, llega a la conclusión de dar mayor credibilidad al informe aportado por la Comunidad Autónoma de la Rioja que a los 
El carácter discrecional-técnico de la fijación de los caudales ecológicos viene además recogido en la exposición de motivos del Real Decreto 638/2016, de 9 de diciembre, que modifica el Reglamento del Dominio Público Hidráulico y el Reglamento de la Planificación Hidrológica, donde se recoge que: "de las diferentes disposiciones analizadas se desprende la complejidad técnica de la materia y, la necesidad de la constante actualización normativa que ha de acomodarse en la medida en que se alcanza un mejor conocimiento técnico de la funcionalidad más adecuada y de la estructura de los ecosistemas acuáticos".

Dejando asentado que en la fijación de los caudales ecológicos encontraremos elementos de discrecionalidad técnica, procede avanzar en el análisis para determinar que estos caudales no se fijarán exclusivamente atendiendo a "asépticos" criterios técnicos, sino que influirán otros elementos con mayor margen de apreciación. Entra en juego lo que podríamos denominar como una "discrecionalidad pura". Bajo este prisma, la Administración hidráulica deberá tomar decisiones con base a criterios tanto extrajurídicos como propiamente jurídicos. Criterios basados en la interpretación de las bases legales, de los principios generales del derecho, y de un juicio global de racionalidad y razonabilidad que debe fundar la toma de decisión. Todo ello, además, condicionado por un proceso participativo y de concertación en el que, sin tener que asumir los planteamientos de los agentes participantes, el Organismo de Cuenca deberá al menos tener en cuenta tales apreciaciones y razonar sus decisiones discrepantes con respecto a los resultados de la participación.

Además del nivel discrecional puro, en la Sentencia que estamos comentando el propio Tribunal Supremo reconoce implícitamente la existencia de elementos de oportunidad que también pueden estar presentes en la fijación de los caudales ecológicos. Entran aquí contenidos valorativos que pueden asociarse a los principios relativos a la gobernanza del agua e incluso a decisiones de política hidráulica que pueden inclinar la balanza hacia la maximización de la variable ambiental o, alternativamente, hacia la maximización de la variable socioeconómica. Una valoración adecuada de estos elementos por parte de quien impulse el proceso de planificación resultará decisiva para la fijación del caudal ecológico en mayor o menor volumen.

En función de todo ello, la Administración hidráulica deberá motivar en los documentos de planificación las razones por las que los caudales ecológicos quedan fijados con uno u otro alcance, siempre bajo el prisma de la interdicción de la arbitrariedad.

En este sentido, reiterada jurisprudencia del Tribunal Supremo determina que el establecimiento de caudales ecológicos debe configurarse "con el menor detrimento posible de los existentes derechos de uso del agua". Es decir, en su fijación deben acogerse criterios de proporcionalidad (adecuación al fin) e intervención mínima, de modo que las posibles restricciones a los derechos de uso ya existentes sean los menores posibles (STS de 11 de julio de 2014 (RJ 2014, 4415) y STS de 5 de diciembre de 2014 (RJ 2014, 6272).

La Sentencia del Tribunal Supremo núm. 387/2019 de 21 de marzo, apunta a la necesidad de alcanzar un balance adecuado entre los principios ecológicos y las demandas existentes, lo que también apunta a la necesaria proporcionalidad en la toma de decisión: "debe existir un equilibrio entre la satisfacción de las demandas de agua y la consideración de los regímenes

otros informes por lo que ha de declararse la nulidad de la ampliación del caudal concedido por el acto administrativo impugnado." 
concesionales, de una parte, y la necesidad de velar por el mantenimiento del caudal ecológico".

De nuevo, el Tribunal Supremo en su Sentencia de 21 enero 2015 RJ $2015 \backslash 459$ admitió su aplicación como instrumento de control de la discrecionalidad para evitar la fijación de caudales ecológicos eventualmente desproporcionados o carentes de base técnica. La Sentencia, sin embargo, no apreció en el caso de autos que se hubiera probado tal circunstancia, pero abrió una importante vía para reducir la discrecionalidad administrativa si se alcanza a probar la falta de correspondencia entre los volúmenes fijados, los objetivos ecológicos y la satisfacción de las demandas. La alegación de caudales desproporcionados se había planteado por la parte actora como una afirmación general, sin aportar prueba alguna ${ }^{6}$.

La jurisprudencia, en definitiva, exige que la valoración realizada por la Administración se realice sobre la base de motivos fundados, debidamente razonados y técnicamente sólidos. No cabe duda que demostrar lo contrario es una cuestión probatoria difícil de materializar con éxito en vía judicial, teniendo en cuenta la presunción de legitimidad que beneficia a los informes y decisiones administrativas.

Entre los principios jurídicos que deberán aplicarse para reducir la discrecionalidad podríamos añadir, junto al citado de la proporcionalidad, otros como el de igualdad (utilización de técnicas homologables para la fijación de caudales ecológicos en todos los planes), equidad o justicia material, solidaridad interterritorial, racionalidad económica, o incluso libertad de empresa, entre otros. Este último, en tanto en cuanto la fijación de los caudales ecológicos debe tener en cuenta el derecho de los ciudadanos a desarrollar actividades económicas basadas en el aprovechamiento del agua, de modo que una regulación que impidiera de raíz el ejercicio de ese derecho podría resultar antijurídica.

\section{La participación y concertación como método que contribuye a la fijación de los caudales ecológicos en el proceso de planificación, sin excluir su fijación unilateral por parte de la Administración hidráulica}

La fijación de los caudales ecológicos en los planes de cuenca es fruto de un proceso participativo en el que se busca la concertación entre la Administración hidráulica, los agentes interesados y el resto de Administraciones implicadas. El objeto no es otro que permitir un mejor conocimiento de la percepción de los agentes afectados y de los problemas a que estos deben enfrentarse con motivo de este tipo de restricciones. Sin embargo, la concertación no presupone una decisión de consenso, puesto que la competencia final para la concreción del caudal ecológico reside en la Administración hidráulica, que actuará de forma unilateral al aprobar el planeamiento de la demarcación. Los usuarios deben ser oídos en el proceso de

\footnotetext{
${ }^{6}$ El Tribunal señala: "una cosa es que se fijen caudales ecológicos (es un contenido obligatorio de los Planes) y se fijen para todas las masas y otra es que los fijados se reputen exagerados. Ahora bien, tal motivo en sí se hace valer a modo de impugnación general, global, cuando lo propio sería probar, como cuestión de hecho que es, que los fijados carecen de proporcionalidad, luego escapan a su conceptuación y finalidad normativamente prevista". En la Sentencia, queda claro que: "se está ante una cuestión de hecho, luego necesitada de una prueba técnica, pericial, que respalde esas alegaciones por lo demás inconcretas (...) en cuanto a la bondad del método hidrológico empleado respecto de masas agua naturales, la pericial acude a expresiones valorativas que no obedecen, a modo de conclusión, a un proceso lógico demostrativo de lo erróneo del método empleado (...)proponiendo lo que se considera un método mejor, pero sin razonar porqué el empleado ofrece resultados erróneos"
} 
concertación y pueden aportar sus análisis y estudios para justificar sus posiciones, pero la decisión será en último término de la Administración, quien, eso sí, deberá motivar sus decisiones.

La jurisprudencia viene indicando que la concertación no equivale a la necesidad de alcanzar un acuerdo; así lo confirma la Sentencia del Tribunal Supremo de 20 de enero de 2015 RJ $\backslash 2015 \backslash 220$, que además define el contenido mínimo de dicho procedimiento. Éste debe contener uno o varios encuentros previos entre la Administración y los sectores afectados en los que se evidencie una decidida voluntad de alcanzar los objetivos e intereses respectivos; en caso de no lograrse una solución consensuada, será la Administración la que fije unilateralmente los caudales ecológicos ${ }^{7}$. En esta misma línea, la Sentencia del Tribunal Supremo de 21 de enero de 2015 (RJ\2015\459) destaca que lo relevante es intentar alcanzar puntos comunes, sin que ello suponga alcanzar un consenso entre las partes. Destaca el Tribunal que "la concertación es un método, no un resultado necesario y normativamente impuesto"; el proceso no debe desarrollarse "sine die", ya que lo que la Ley pretende es que se busque el consenso, no que necesariamente se alcance: "una cosa es que se busque la concertación y otra que el Plan deba ser fruto de un consenso (...) lo que no merma la capacidad decisoria final de la Administración"».

Esta posición jurisprudencial es a nuestro juicio coherente con el principio de indisponibilidad de la competencia, que obliga a la Administración a aplicar la Ley dejando muy poco espacio a la transacción, a diferencia de lo que ocurre en el ámbito jurídico privado.

Finalmente, la Sentencia de 20 de noviembre de 2015 (RJ/2015\5493) extiende la concertación más allá del momento de aprobación del plan. El esfuerzo de concertación no debe limitarse a su elaboración, también debe estar presente en cualquier revisión sustancial que se produzca del mismo y pueda afectar al caudal ecológico, lo que resulta coherente con lo declarado por el Tribunal Constitucional, en STC 195/2012 (RTC 2012, 195) respecto del plan integral de protección del Delta del Ebro, donde el Alto Tribunal ordenó que la revisión se realizara "a través del mismo cauce procedimental y con la intervención de los mismos órganos que están previstos para cualquier otra revisión”.

\section{Responsabilidad patrimonial del Estado ante las restricciones que se deriven de la imposición de caudales ecológicos sobre derechos adquiridos al aprovechamiento de las aguas del Tajo}

La aplicación sobrevenida de limitaciones derivadas del establecimiento de caudales ecológicos puede dar lugar a responsabilidad patrimonial de la Administración, obligando a compensar a los perjudicados. El fundamento legal de esta afirmación radica en el artículo $65.1 \mathrm{~d}$ ) del TRLA, donde se prevé la revisión de concesiones en caso de que sea precisa su adecuación a los planes hidrológicos, y se establece que dicha medida puede dar lugar a una compensación económica atendiendo al alcance del proceso de adecuación, de acuerdo con el apartado 3 del citado precepto.

\footnotetext{
${ }^{7}$ En idéntico sentido: Sentencias de 2 de julio de 2014 (RJ 2014, 4002) (rec. no 328/2013) y 11 de julio de 2014 (RJ 2014, 4415) (rec. no 329/2013).

${ }^{8}$ También, Sentencias de esta Sección de 2 (RJ 2014, 4002) y 11 de julio de 2014 (RJ 2014, 4415), recursos contencioso administrativos 328 y 329/2013 respectivamente.
} 
Cierto es que los usuarios del Trasvase Tajo Segura no son formalmente concesionarios de la cuenca del Tajo; su derecho es de configuración legal, pero su situación sería equiparable a la de los titulares de concesiones de aprovechamiento que, como consecuencia de la imposición de caudales ecológicos, experimentan un perjuicio en sus derechos adquiridos. Siendo así, los usuarios del Trasvase podrían plantear una pretensión de responsabilidad patrimonial de la Administración con motivo de la eventual aprobación de un plan que, incrementando los caudales ecológicos actuales, conllevara una disminución de sus dotaciones. Resultaría lo anterior de una interpretación extensiva y analógica (in bonus) de lo establecido en el citado artículo para las concesiones.

Sobre la aplicabilidad de este precepto a las restricciones impuestas por la imposición de los caudales ambientales, la importante Sentencia del Tribunal Supremo de 12 de diciembre de 2014, RJ 2014/6702 desestimó las alegaciones de la abogacía del Estado, que mantenía que los caudales ecológicos no podían dar lugar a modificaciones en los títulos concesionales susceptibles de indemnización puesto que su determinación en el planeamiento, debido a su condición de restricciones y no usos, debía considerarse como "una limitación estructural de los sistemas de explotación"; es decir, un límite legal que ya pesaba sobre las concesiones antes de la aprobación del plan hidrológico? ${ }^{9}$.

En otras palabras, del contenido de esta Sentencia se deduce que aun siendo los caudales ecológicos restricciones y no usos, ello no significa que su imposición tenga un carácter meramente declarativo, en el sentido de que dichas restricciones ya pesaran sobre la cuenca antes de su establecimiento, de modo que el plan simplemente vendría a reconocerlas. Por el contrario, su determinación en los planes hidrológicos preconstituye una nueva situación jurídica que los usuarios de la cuenca no tenían que soportar, por lo que, en aplicación de los principios de seguridad jurídica y confianza legítima, resultaría teóricamente posible la generación de responsabilidad patrimonial.

Existe numerosa jurisprudencia del Tribunal Supremo que reconoce esta posibilidad, aunque en las Sentencias analizadas, que enfrentan esta cuestión de manera genérica con motivo de impugnaciones de planes hidrológicos de cuenca o demarcación, no se ha condenado a la Administración a realizar dichas compensaciones ${ }^{10}$. El motivo no ha sido la eventual antijuridicidad de dicha compensación, sino el carácter prematuro de la pretensión ${ }^{11}$. Los recurrentes impugnaban la ausencia en los planes hidrológicos de normas destinadas a regular las compensaciones, a lo que el Tribunal Supremo, sistemáticamente, declara que las

\footnotetext{
${ }^{9}$ El Tribunal mantiene que la argumentación de la abogacía del Estado "choca con el contenido del propio texto reglamentario, que se mete explícitamente a aceptar supuestos en los que por causa del respeto al caudal ecológico, sí procede la indemnización sugerida en el artículo 65.3. Es por eso que no cabe admitir que por vía reglamentaria y concretamente de planificación, se entre en la delimitación de un precepto legal que contiene los elementos suficientes para su aplicación y desarrollo jurisprudencial y menos en términos de clara contradicción conceptual, como la que hemos dejado indicada".

${ }^{10}$ STS de 11 de junio de 2015, recurso 583/2012; 27 de julio de 2015, recurso de casación 3499/2013; 24 de enero de 2014, recurso de casación 5682/2010; 23 de septiembre de 2014, recurso de casación 582/2012.

${ }^{11}$ La Sentencia de 11 de julio de 2014 (RJ 2014, 4040) (recurso 329/2013), claramente indica que es: "prematuro al impugnar el Plan, pretender que la Sala determinase, con carácter general y abstracto - desvinculado de la impugnación de los supuestos de revisión de las concesiones - los casos en los que ha de indemnizarse por la modificación de los caudales ecológicos en función de la fecha de la concesión: tal cuestión debe suscitarse y resolverse cuando se impugne la revisión de cada concesión administrativa (artículos 65.3 y 65.1.c) TRLA EDL (...) Se trata, por tanto, de motivos de impugnación basados en la exigibilidad prematura y directa de una reparación por aplicación del plan hidrológico impugnado"
} 
indemnizaciones, aunque pudieran ser procedentes, deben determinarse en el momento de la ejecución del plan, es decir, cuando las concesiones resulten realmente afectadas por la implantación y ejecución del mismo ${ }^{12}$. La Jurisprudencia, también por este motivo, viene desestimando los recursos que pretenden la anulación de planes hidrológicos atendiendo a la ausencia de una memoria o estudio económico que permita valorar los perjuicios que podrían causarse a los usuarios existentes ${ }^{13}$.

La Jurisprudencia declara que los concesionarios afectados por los caudales ecológicos ostentarían el derecho a instar su revisión por inadecuación al plan hidrológico. Se trataría de un derecho ex lege que no admite modulaciones o matizaciones en su régimen jurídico de una demarcación hidrográfica a otra, por lo que los planes de demarcación no deben entrar en su regulación. Los planes hidrológicos no deben incluir determinaciones que puedan limitar o condicionar dicho derecho; el derecho a la revisión de la concesión y por tanto, de la consiguiente indemnización, tiene que resultar de un momento posterior en el que, en ejecución del plan, se constaten tales restricciones ${ }^{14}$. Los daños antijurídicos a los títulos de aprovechamiento existentes causados por la imposición de estas restricciones quedarán determinados en el procedimiento correspondiente ${ }^{15}$, y las posibles indemnizaciones vendrán justificadas en base a los principios de seguridad jurídica y confianza legítima ${ }^{16}$.

Una clarificadora Sentencia del Tribunal Supremo de 11 de julio de 2014 (RJ 2014, 4415) distingue tres situaciones: en primer lugar, las concesiones administrativas posteriores a la entrada en vigor del plan hidrológico de la demarcación, las cuales deberán sin más ajustarse a sus previsiones sobre los caudales ecológicos. En segundo lugar, las concesiones administrativas anteriores a la entrada en vigor del plan que hayan incluido en su clausurado una previsión de adaptación al futuro plan; a estas les será de aplicación el nuevo régimen de los caudales ecológicos desde que se notifique a cada titular sin ningún tipo de compensación. Por último, pueden existir concesiones administrativas anteriores a la entrada en vigor del plan en cuyo clausurado no se hubiera incluido ninguna previsión de adaptación con respecto de los planes venideros"; estas últimas serían las únicas que podrían dar lugar a compensaciones en tanto en cuanto se cumplan las condiciones legales correspondientes.

\footnotetext{
${ }^{12}$ El Tribunal Supremo, en efecto, tiene dicho que: "será en el seguimiento, y tras el Plan, cuando podrán interesarse esas revisiones cuya exigencia opera, como se ha dicho, "ex lege", luego si bien no hay un deber jurídico de incorporar tal previsión al Plan, esto no implica su exclusión”. Sentencia 17 de junio de 2014 (RJ 2014, 3183) Recurso 343/2013.
}

${ }^{13}$ Dice la Sentencia de 21 enero 2015 RJ $\backslash 2015 \backslash 459$ (también la Sentencia de 11 julio 2014 RJ $\backslash 2014 \backslash 4040$, que coincide en este planteamiento): "en lo que ahora interesa, si no hay un estudio o una memoria como exigencia formal o procedimental, no es porque se esté ante una omisión procedimental, sino porque no se estima pertinente: queda pospuesto al proceso de implantación y es, en todo caso, una cuestión ligada al fondo tal y como más abajo se expondrá".

\footnotetext{
${ }^{14}$ Sentencia del Tribunal Supremo de 20 de enero de 2015 RJ $2015 \backslash 220$.

15 Toda esta doctrina es a su vez recogida en las Sentencias del Tribunal Supremo de 21 de enero de 2015 RJ/2015/459 y de 27 de abril de 2015 RJ/2015/2194.
}

\footnotetext{
${ }^{16}$ En este sentido, la Sentencia del Tribunal Supremo de 2 de julio de 2014, RJ/2014/4002 dice: "en su caso y cuando sea procedente como consecuencia de una afección singular, el principio indemnizatorio proclamado por el art. 63 de la TRLA (RCL 2001, 1824, 2906) cubre las referencias a la seguridad jurídica y la confianza legítima que se invocan en el alegato".
} 
En la Jurisprudencia menor hemos localizado una interesante Sentencia del Tribunal Superior de Justicia de Aragón de 19 de abril de 2018, RJCA 2018/848, que se encuentra recurrida ante el Tribunal Supremo, de excepcional importancia en orden a la regulación de las posibles compensaciones. Esta Sentencia acuerda "reconocer el derecho de la recurrente a la indemnización", que deberá fijarse en ejecución de sentencia, con motivo de las limitaciones derivadas de la imposición de caudales ecológicos. El Tribunal Supremo ha admitido el recurso frente a esta Sentencia debido a la existencia de interés casacional para la formación de jurisprudencia. Dice el Auto de 19 noviembre 2018, JUR 20181314599 , por el que se admite el recurso: "la cuestión que se entiende que tiene interés casacional objetivo para la formación de jurisprudencia consiste en determinar si cabe equiparar el establecimiento de los caudales ecológicos fijados por los planes hidrológicos de cuenca al supuesto de que sea precisa una adecuación de la concesión a los mismos, dando lugar directamente al reconocimiento de indemnización al concesionario perjudicado por aplicación del artículo 65.3 del Texto Refundido de la Ley de Aguas”.

Teniendo en cuenta la controversia suscitada por la anulación del Plan de la Cuenca del Tajo, precisamente por la falta de fijación de caudales ecológicos, es previsible que su futura fijación pueda afectar a los usuarios del Trasvase Tajo-Segura. Ciertamente, los usuarios del Trasvase no son titulares de concesiones sino de un título legal de aprovechamiento, pero pueden sufrir limitaciones comparables a las de un concesionario de la cuenca, por lo que sus derechos no debieran verse lesionados con motivo de la imposición de caudales ecológicos desproporcionados. De ser así, podría derivarse una pretensión de responsabilidad patrimonial.

\section{Conclusiones}

La Sentencia del Tribunal Supremo 309/2019 de 11 de marzo, relativa al plan hidrológico del Tajo, en ningún momento pone en cuestión la continuidad del Trasvase Tajo-Segura ni del marco normativo que lo sustenta. El riesgo radica, sin embargo, en su desnaturalización o vaciamiento de contenido, que se produciría si fuera impuesta una desproporcionada regulación de los caudales ecológicos del río Tajo. La elevación de estos caudales podría condicionar al máximo los trasvases, al suponer mayores desembalses y la consiguiente disminución de las reservas en cabecera. En definitiva, tal determinación, sin derogar o modificar la normativa legal vigente, limitaría notablemente en la práctica la posibilidad de trasvasar caudales, quedando reducida dicha opción a años de gran pluviometría. Tal configuración de los caudales ecológicos supondría a nuestro juicio la nulidad del plan hidrológico de la demarcación por infracción del principio de reserva de ley.

La Sentencia ordena a la administración hidráulica fijar nuevos caudales ecológicos, lo que en palabras de propio Tribunal podrá hacerse mediante una revisión del Plan del Tajo acordada por el Consejo de Agua de la Demarcación, conforme a lo establecido en el artículo 89.1 del RD. 907/2007, por el que se aprueba el Reglamento de Planificación Hidrológica (es decir, cuando cambios o desviaciones en datos hipótesis o resultados aconsejen la revisión anticipada del plan), o bien en la próxima revisión del plan hidrológico en el siguiente ciclo de planificación. Existe un riesgo relativo de que los nuevos caudales ecológicos sean fijados al margen del futuro ciclo de planificación, de manera anticipada, si se acuerda la primera de las opciones comentadas. 
La Sentencia desestima la pretensión de la parte actora en cuanto a la fijación directa, en ejecución de sentencia, de los caudales ecológicos propuestos en la ETI de 2010. La concreción de dichos caudales por parte del Tribunal resultaría contraria al ordenamiento jurídico, puesto que comportaría el ejercicio de funciones materialmente administrativas, lo que sólo corresponde a la Administración hidráulica a través de los cauces legales establecidos.

El Tribunal tampoco prejuzga en absoluto que los caudales de la ETI de 2010 deban ser los que finalmente se fijen en el próximo ciclo de planificación hidrológica. Queda asentado el criterio del Tribunal en cuanto a la ausencia de caudal ecológico en el PHT en las 4 masas de agua estratégicas del río Tajo (sólo se fijan caudales circulantes), pero las cifras correspondientes a los caudales ecológicos de la ETI de 2010 no son más que datos incorporados a un documento de trámite elaborado con motivo de la tramitación del Plan, que finalmente no fue aprobado en aquellos términos. En definitiva, esas cifras no son vinculantes o determinantes para la futura especificación del caudal ecológico de dichas masas, en el próximo ciclo de planificación hidrológica.

La futura determinación de los caudales ecológicos deberá ser el resultado de un proceso con dos elementos decisivos: de un lado, la necesaria aportación de estudios técnicos sobre la cuenca, destinados a determinar con qué volumen de caudal ecológico circulante se podrán mantener los recursos piscícolas, la flora de ribera y, en general, el buen estado ecológico de las masas de agua del río Tajo (discrecionalidad técnica); de otro, el resultado del proceso participativo en el que, mediante concertación, que no necesariamente consenso o acuerdo, se deberán tener en cuenta las variables no exclusivamente técnicas, sino de carácter discrecional puro e incluso de oportunidad, a través de las cuáles deberán valorarse, junto a los aspectos ambientales, los de carácter socioeconómico.

Debido a los componentes de discrecionalidad pura e incluso de oportunidad presentes en la concreción de los caudales ecológicos, las posiciones de partida de quienes deben decidir sobre esta cuestión resultarán decisivas. Téngase en cuenta que en las ETI se ponen en relación al menos dos escenarios, el "escenario de maximización de los valores ecológicos", que obviamente tiende a la elevación de tales caudales, y el "escenario de maximización de criterios socioeconómicos", de acuerdo al cuál se busca que la fijación de dichos niveles, sin poner en riesgo la biodiversidad del espacio ni el estado ambiental de la masa, permita lograr un equilibrio con las actividades socioeconómicas que dependen del aprovechamiento de dichos recursos. Se trata de una opción entre variables completamente legítimas, lo que es consustancial con las decisiones de tipo discrecional, donde hay siempre un margen de apreciación entre opciones jurídicamente posibles.

La utilización en la Sentencia del término razones de "oportunidad" como elemento que podría entrar en juego en la fijación del caudal ecológico refuerza todavía en mayor medida lo comentado, ya que dibuja un margen de discrecionalidad particularmente amplio en el que cabrían incluso elementos de política hidráulica en la toma de decisión. Es decir, que dentro de la horquilla mínimo-máximo que permite el mantenimiento de la vida de las especies, puede haber un margen de apreciación elevado.

Aunque los elementos reglados, discrecionales técnicos, discrecionales puros y de oportunidad estarán presentes en la fijación de los caudales, el límite de todo ello radica en la interdicción de la arbitrariedad. La Administración hidráulica deberá motivar en los 
documentos de planificación las razones de la fijación de los caudales en un sentido u otro, con el citado límite de la arbitrariedad y el posible control jurisdiccional posterior.

En este sentido, y de acuerdo con una reiterada jurisprudencia del Tribunal Supremo, la especificación de los caudales ecológicos debe configurarse "con el menor detrimento posible de los existentes derechos de uso del agua". Es decir, en la cuantificación de los caudales ecológicos deben acogerse criterios de proporcionalidad e intervención mínima, de modo que las posibles restricciones a los derechos de uso ya existentes sean los menores posibles. También resultan de aplicación otros principios como la equidad, igualdad ante la Ley (todos los planes deberían seguir una metodología homogénea para la fijación de caudales ecológicos), solidaridad interterritorial, seguridad jurídica, confianza legítima, libertad de empresa, racionalidad y razonabilidad.

Todos estos principios deberán ser tenidos en cuenta en el proceso de aprobación del plan, y los agentes interesados deberían hacerlos valer con el apoyo de los informes técnicos, jurídicos y económicos correspondientes; no bastan alegaciones genéricas a estos principios, ya que cualquier argumentación debe fundarse en sólidos fundamentos técnicos y socioeconómicos. Todo ello para alcanzar un caudal ecológico realmente justo y que tenga en consideración todas las variables.

Es necesario destacar, como hace reiteradamente la jurisprudencia, que los caudales ecológicos no son un "fin en sí mismo", tienen un contenido instrumental destinado exclusivamente a mantener las buenas condiciones de la masa de agua. Si esta masa está ya en buen estado, no parece razonable incrementar tales caudales, puesto que dicha medida resultaría innecesaria y posiblemente desproporcionada; como se ha dicho, el caudal ecológico no es más que un instrumento para alcanzar dicho fin o mantenerlo. La jurisprudencia reconoce que los caudales ecológicos deben ser también establecidos para las masas en buen estado, no sólo para las masas ya alteradas, pero ello no significa que puedan fijarse caudales desproporcionados que, por innecesarios, no aporten mayor protección a la masa de agua.

Además, hay que valorar que el deterioro de las masas de agua no se limita a cuestiones de cantidad, sino muy sustancialmente a problemas de calidad, que no deben enfrentarse con un mayor caudal, lo que sería en cierto modo atajar la contaminación con una suerte de dilución de los vertidos existentes. Recuérdese que la dilución de los vertidos no es precisamente una solución amparada por nuestro ordenamiento. No es aceptable que para mejorar la calidad de una masa degradada por agentes contaminantes externos simplemente se incremente el caudal circulante; habría, por el contrario, que atajar las fuentes de contaminación.

La aplicación sobrevenida de limitaciones derivadas del establecimiento de caudales ecológicos puede dar lugar a responsabilidad patrimonial de la Administración, obligando al establecimiento de compensaciones a los perjudicados. Aun siendo los caudales ecológicos restricciones y no usos, ello no significa que su imposición tenga un carácter meramente declarativo, en el sentido de que dichas restricciones ya pesaran sobre la cuenca antes de su establecimiento, de modo que el plan simplemente vendría a reconocerlas; por el contrario, su determinación en los planes hidrológicos preconstituye una nueva situación jurídica que los usuarios no tenían inicialmente que soportar, por lo que en aplicación de los principios de seguridad jurídica y confianza legítima, resultaría teóricamente posible la generación de responsabilidad patrimonial si su imposición conlleva la revisión sobrevenida de sus derechos de aprovechamiento. 
Esta garantía debería extenderse a los usuarios del Trasvase que, si bien no son formalmente concesionarios, ostentan un derecho de configuración legal que también debe protegerse. La concreción económica de estos derechos, como señala la jurisprudencia del Tribunal Supremo, no puede realizarse en el momento de aprobar la planificación de la demarcación, sino en un momento posterior, cuando de la aplicación del plan se derive una revisión de los títulos de aprovechamiento preexistentes, y se acredite el perjuicio resultante y la relación causal.

\section{Agradecimientos}

El presente estudio ha sido realizado con la financiación de la Cátedra del Agua de la Universidad de Alicante-Diputación Provincial de Alicante (2019).

\section{Referencias}

Embid Irujo, A. (1994). Usos del agua e impacto ambiental: evaluación de impacto ambiental y caudal ecológico. Revista de Administración Pública, 134, 109-154.

Molina, A., Melgarejo, J. y López, I. (2014). El memorándum sobre el trasvase Tajo-Segura. Modelo de resolución de conflictos Hídricos. Revista Aranzadi de Derecho Ambiental, 29, 23-48.

Briso Montiano, L. y García Jiménez, M.A. (2014). Del caudal mínimo al caudal ecológico a través del régimen concesional. Congreso Nacional de Medio Ambiente (CONAMA), 2014. Madrid: CONAMA.

Sastre Beceiro, M. (2010). Proceso de concertación de los caudales ecológicos. XII Congreso Nacional de Comunidades de Regantes de España. Tarragona: FENACORE. 